\title{
Enable Better and Timelier Decision-Making Using Real-Time Business Intelligence System
}

\author{
Darshan M. Tank \\ Department of Information Technology, L.E.College, Morbi-363642, India \\ Email:dmtank@gmail.com
}

\begin{abstract}
Today's businesses need support when making decisions. Business intelligence (BI) helps businesses to make decisions based on good pre-analysis and documented data, and enables information to be presented when and where the decisions need to be made. Real time business intelligence (RTBI) presents numbers in real time, providing the decision makers at the operational and tactical layers with data as fresh as it can be.

By having accurate, fresher and a bigger amount of data, businesses will be able to make decisions in a faster pace, and eliminate tedious complexity of the decisionmaking process.

The objective of this research is to show that a real time business intelligence solution would be beneficial for supporting the operational and tactical layers of decision-making within an organization. By implementing an RTBI solution, it would provide the decision-maker with fresh and reliant data to base the decisions on. Visualization of the current decision processes showed that by adding a real time business intelligence solution it would help eliminate the use of intuition, as there would be more data available and the decisions can be made where the work is performed.

The aim of this research is to contribute by visualizing how a real time business intelligence solution can shorten a complex decision process by giving the correct information to the right people. Organizations need to address potential challenges as part of a pre-project of a real time business intelligence implementation.
\end{abstract}

Index Terms-Business Intelligence, Data and Knowledge Mining, Data Warehousing, Real-Time Data Warehouse, Decision Support System, Information Retrieval.

\section{INTRODUCTION}

Technology is changing rapidly, and IT is becoming a more integrated part of businesses' strategies and vision. As businesses are becoming more and more competitive, there is a need for technology that can assist businesses in reaching their goals and to be able to compete in a rougher market. In order to do that, decisions has to be made at a fast pace, with sufficient and reliable data [2].

There are two main factors affecting the decisionmaking within organizations, and these two factors are intuition and rationality. Research has shown that the use of "gut-feeling" in strategic decision-making is especially prevalent within the computer industry, but that it is still important in other industries.

By using a decision-support system, one will be able to reduce the use of factors such as intuition when making decisions, by having a better data foundation to base the decisions on. One decision support system that is becoming more and more used is business intelligence (BI). Business intelligence can be defined as: “...the process of turning data into information, and then turning it into knowledge, and it is a process that involves getting data in and getting data out.

Little research has previously been done on how a real time business intelligence solution can benefit an organization in means of changing current decision processes. The objective of this research is to show why there is a need for a real time business intelligence solution and how that can change the current decision processes and make them more efficient. Further it indicates that there are challenges to the current decision processes that need to be addressed [3].

Many decision processes were affected by the lack of fresh and reliable data available to the decision-maker. The factor of intuition, especially the use of a "gutfeeling" was a contributing factor to the decision processes. There is a need for a real time business intelligence solution because the employees do not have the most reliable and fresh information to make decisions at the operational and tactical layers. Furthermore there are so many challenges with the current decision processes that would also need to be addressed in order to change the current processes.

By adding an additional layer to business intelligence, the real time layer, you get real time business intelligence. With the real time layer businesses will be able to receive fresh and accurate data at all times, to support their decision-making processes connected to their strategies and goals. Such a system can help eliminate blind spots within the organization, and help gain competitive advantage.

\section{DeCISION-MAKING}

\section{A. The Decision-Making Process}

The decision-making process follows a series of steps.

1) Intelligence 
The intelligence phase is where the decision-maker examines the reality, in order to identify and define the problem. The decision-maker is searches for conditions that call for a certain decision.

\section{2) Design}

This phase concerns trying to find or develop and analyze possible courses of action for the rest of the process. The design phase involves creativity, meaning that you are searching for alternative solutions, and then analyzing these different solutions.

\section{3) Choice}

In the choice phase, the actual decision and the commitment to follow a certain course of action is made. The decision-maker compares the best solutions that are available, and then selects the best of these solutions.

\section{4) Implementation}

In the final phase, the implementation phase, we put the solution we have worked on in to action. The following diagram illustrates the process:

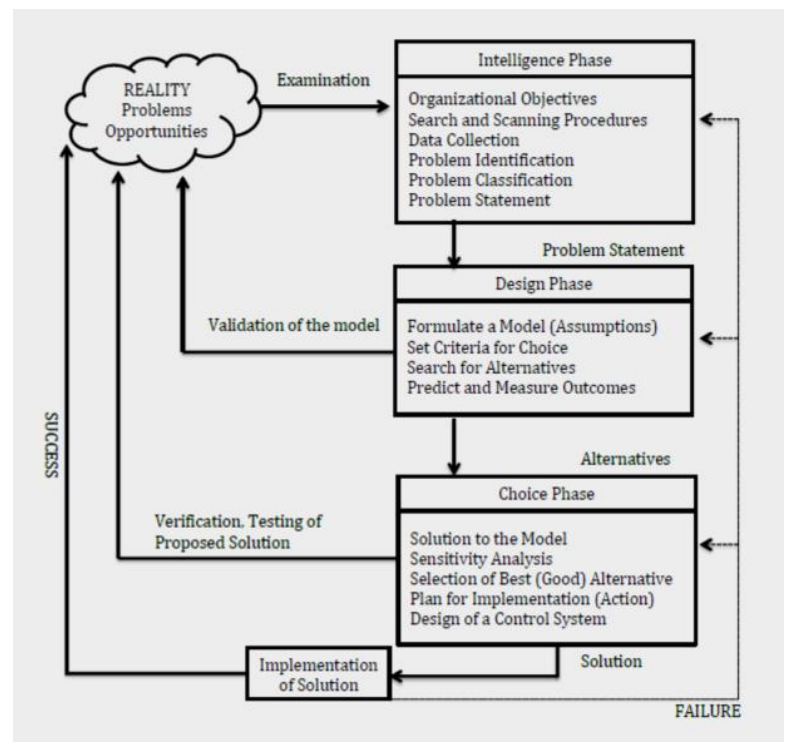

Fig. 1. Four steps of decision-making process

It is important to remember that after the implementation, the process does not stop. Continuous monitoring of the processes is crucial in all organizations, to be able to always achieve the best results and to gain competitive advantages [7].

\section{B. The Latency and Value of Data}

In most cases, low latency (i.e., fresh) data has more value than high latency data. This is why the movement to real-time BI is appealing. There are three kinds of latency in data warehouse. Data latency is the length of time between when an event occurs and when the associated data is stored in the data warehouse. Analysis latency is the time between when the data is stored and when it is analyzed and made available to applications and users. Decision latency is the time from when the information is available until some action is taken on it.
These three sources of latency are additive and result in total latency.

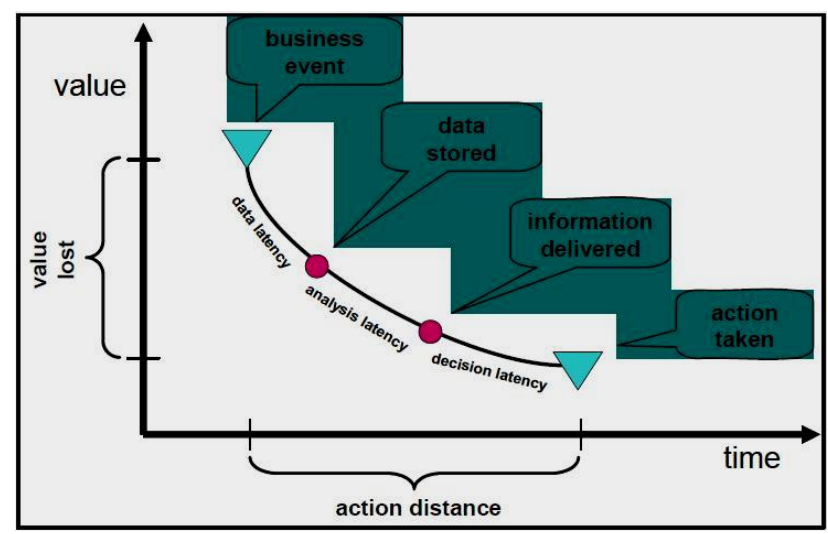

Fig. 2. Types of Latency

Reducing data and analysis latency depends primarily on technical solutions. Reducing decision latency requires changes in business processes and how people use information in performing their jobs. Providing fresher data does not create business value unless it is used in a timely manner. Dealing with decision latency is usually more challenging than data and analysis latency [8].

\section{BUSINESS INTELLIGENCE}

In order to assist businesses with making decisions, decision support systems (DSS) were introduced in the beginning of the 1970's. Over the years many applications emerged and expanded the domain, and in the early 90's business intelligence was introduced (BI). Business intelligence was born in order to satisfy the requests of managers for efficiently and effectively analyzing the data in the enterprise, in order to understand the situation their business is in, and to improve the decision-making process. Business intelligence can be defined as "the process of turning data into information, and then turning it into knowledge".

BI is seen as the solution that will help organizations leverage their information in order to make intelligent decisions. It is a process that involves getting data in and getting data out, and was designed to support decisionmaking [12].

Business leaders around the world have an enormous amount of data to work with, and a lot of this information is also of bad quality. The information that an enterprise possesses is mainly $90 \%$ unstructured and $10 \%$ structured and business intelligence aims to solve that problem. BI gathers data from multiple sources in the organization through a data warehouse, and these sources can be ERPsystems, CRM, SCM, and so on.

Decision-making and strategic formulation no longer need to rely on knowing "what happened", but can now be supported by comprehensive intelligence as "what happens now" and "what is most likely to happen". There are three broad approaches that are helping to build BI solutions that provide employees who work with 
information the right to make better-informed decisions that are more in line with corporate objectives. These three approaches are: simplicity and relevance, agility, and integration, and will contribute to improved decisionmaking [15].

By looking at the "Business Intelligence Framework" (Fig. 3), we get a better overview of Management's primary activities: getting data in and getting data out.

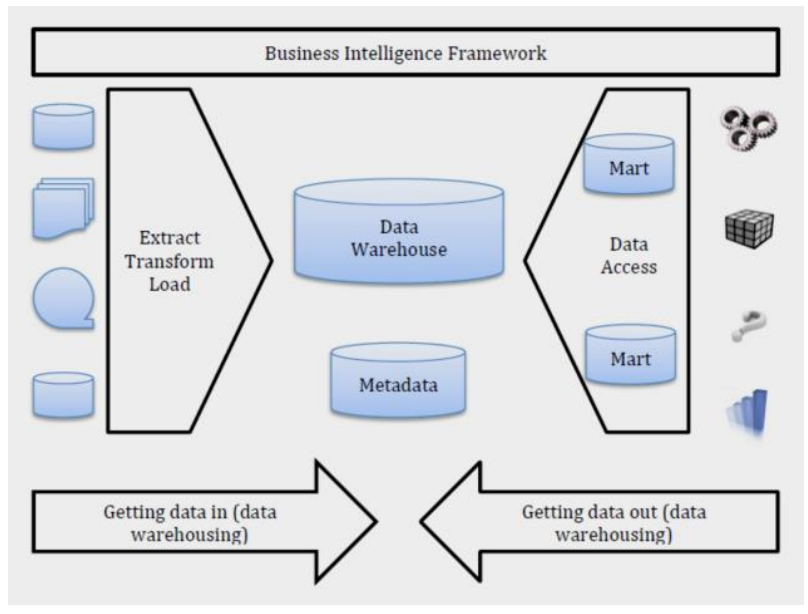

Fig. 3. Business Intelligence Framework

With the underlying architecture in place, and a BI solution, the process will go as follows:

- Information is extracted from the various information systems that an organization holds.

- The information is transformed into static data and stored in the data warehouse. As the data is static, it cannot change.

- Business intelligence collects that data, and turns it into useful information and then knowledge by showing the data in graphs, cubes and so on.

BI can be an enabler to an already competitive environment by providing the decision-maker with more reliant information. BI is changing how companies are managed, decisions are made, and people perform their Job.

\section{REAL-TIME BuSINESS INTELLIGENCE}

As an additional layer to business intelligence, real time business intelligence (RTBI) can be added to give the businesses information that is fresh and urgent. For businesses to be able to improve their performance and to follow their competitors and the market trends, it is becoming more and more important for businesses to get information in real time. A system that provides the user with real time information can help eliminate blind spots within the business, and being able to view the information fast enough is a necessity. The purpose of real time BI is to increase revenues and decrease costs. Companies that successfully implement real time BI can dramatically improve their profitability.
Real time does not always mean instantaneously, but it means that the data is as fresh as the business needs it to be. The meaning of real time does not have to mean data that is only a few seconds old, but that the data is as fresh as it can be. Real time business intelligence is much more than time, it also conveys a rich sense of urgency within the organization. Real time business intelligence can also be envisioned as a seamless transition from data to information, and then into action. When a business is to implement such a tool, it is critical that the business understands it and can see the real value of such an implementation. Businesses need to understand that the purpose of BI is not to achieve results quickly, but to make sure it is creating value for the organization. Business intelligence provides companies with a holistic overview of their business, and monitors the financial health of the organization [12]. However, taking real time measures of the operational level of an organization will give the business the chance to constantly measure their performance. Whilst strategic BI analyses historical data, operational $\mathrm{BI}$ gives measures in real time, enabling the organization to make decisions based on what is happening right now as the results are immediate.

In order to be successful with real time BI, organizations must focus on and overcome both organizational and technical challenges. Organizational challenges include having the support of the organization and top management, and having financial support. Technical challenges include having the correct hardware and software available, as well as having the right tools to support the implementation [13].

The case with today's business intelligence solutions is that they do not go beyond reporting. The vision of RTBI is the seamless transition from data into information into action. Today's BI systems have trouble realizing this, and basically suffer from two bottlenecks; there are not enough experts and analysts to run the software, thus hindering the transition from data to information.

The following figure (Fig. 4) illustrates current business management systems and how manual intervention breaks down the information flow between strategic, tactical and operational layers.

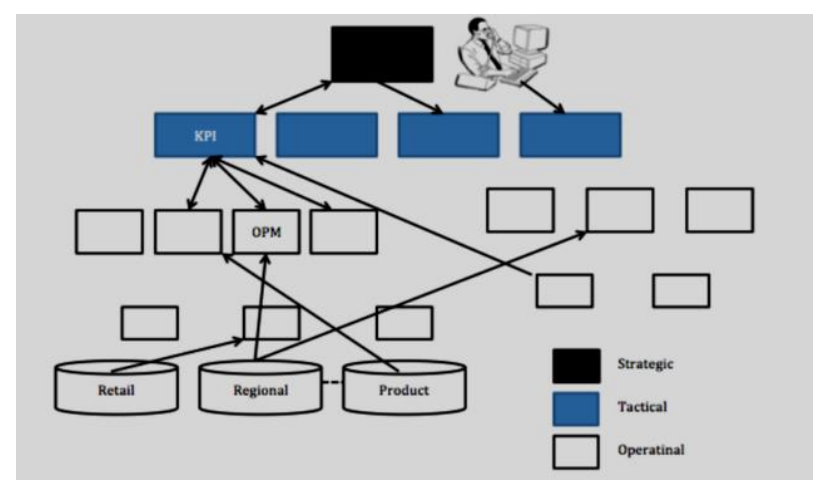

Fig. 4. Strategic, tactical and operational layers

The challenge here is how to automate the manual processes by using intelligent technologies, and how to represent this data as real time. This is also a challenge 
when there are several layers that need to be automated.

RTBI will give decision-makers even more control, expanding to the dashboard metaphor by adding "a steering wheel, levers and pedals to the control suite, and enable business managers to change parameters of processes in real time". There are technical challenges to make such a work, dividing these challenges into three layers: an analytical layer, a data integration layer and an operational layer. In the analytical level, there will be no need for experts, as the "analyst-in-the-middle" represents a time lag within this process. The RTBI framework would look like this (Fig. 5):

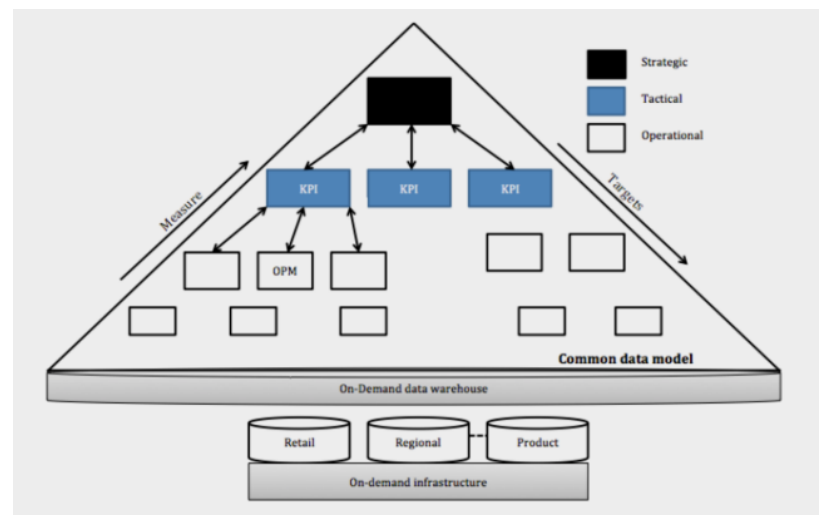

Fig. 5. Propose on RTBI Framework

By adding the layer of real time business intelligence to a decision support system, the hope is to gain benefits such as a more effective decision process and to reduce costs in the organization.

\section{DATA WAREHOUSING}

Data warehousing is seen as an important enabler for business intelligence, because BI is used to analyze data that is stored in the warehouse. In fact, it is said that data warehouse is the core component of a business intelligence infrastructure foundation, and it contains all transactional data that the organization holds, which is specified for querying and reporting. Managers and other decision-makers in an organization need quick access to correct and consistent data throughout the enterprise, which they leverage in order to improve business processes and performance. Business environments are becoming more competitive and global, and decisions are made based on what data is available to the decisionmakers, and that data can be stored in a data warehouse.

A data warehouse is a collection of data where all transactional information of an organization is stored, but it is not the same as a database. The main difference is that databases are designed and optimized to store data, whereas data warehouses are designed and optimized to respond to analysis questions that are critical for business. Data warehouses are considered to be powerful problemsolving tools that enable easy access to information. The information that is stored in a data warehouse is static, and cannot change. This is mainly because information stored in a data warehouse is used to analyze the organization, which is difficult to do if the information stored continues to change [22].

The end-users of the data warehouse are users such as analysts, managers and operational personnel, and there are data suppliers who are responsible for providing them with the data. A data warehouse has many characteristics, and all types of DW's share the following nine characteristics:

1. Organized data

2. Consistency in data

3. Time Variant - data is kept over a longer period

4. Nonvolatile

5. Relational structure

6. Client/Server architecture

7. Web-based support

8. Integration using various sources

9. Real time capabilities

There are many benefits of a data warehouse, and these are both business and IT related. When looking at it from the business perspective, decision-makers are able to make better decisions because of access to precise information, whilst from the IT-perspective the information is delivered more effectively. Although data warehouses provide several advantages for an organization, many of these projects fail because of the complexity of the development process and the organizational focus on goals and strategies. One major problem in building a data warehouse is to identify and consider information needs of potential users. There are many factors that are important when building, implementing and running a data warehouse. The relationship between the DW and BI (Fig. 6) as following:

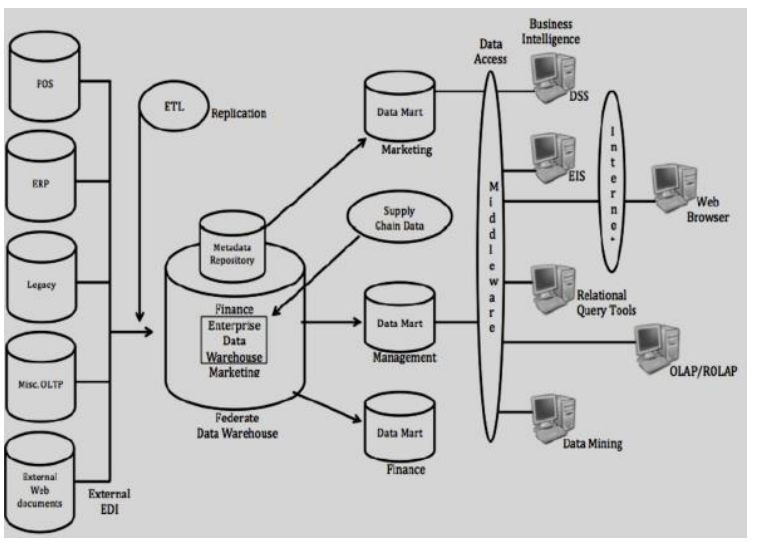

Fig. 6. How BI systems work

On the left side of Fig. 6, data is collected from the different departments of the organization, before they are transformed into standard formatting. After being transformed, the data is loaded into the data warehouse. This process is called Extract, Transform, and Load (ETL). After the data has been cleaned and stored, it is transformed into static data, and can be used for analytical and operational purposes. By using a BIsolution, the organization will then be able to collect and use that specific data to create reports, analysis and so on. 


\section{KEY PERFORMANCE INDICATORS}

As business environments are shifting at a faster pace than before, and are more competitive, it is crucial that they measure their performance. Many businesses are measuring their performance, but they fail to manage their measurements to ensure that they do in fact reflect their organizational context. To ensure that a decision support system gives an organization the correct benefits, it is important that the right measuring creates value for the organization [28].

The organizational context of a business changes rapidly, and it is important that the measuring reflects that change. A strategy is crucial for any organization, and when that strategy is in place, KPI's are tools that can be to measure the performance and success of that strategy, to help the business to reach its goals. Traditionally businesses have measured their performance solely in financial terms. This limited approach has been challenged, with the introduction of the concept of key performance indicators (KPIs) for non-financial results. Key performance indicators measure the performance of a specific process, and whether it is done right.

When it comes to measuring, all levels of an organization can be measured, all the way from the floor level to the $\mathrm{C}$-level executives. Indicators that can be measured are; user acceptance, employee satisfaction, quality assurance, and testing. Performance measurement of a specific activity within an organization will lead to the ability to make better decisions regarding what changes should be made.

Deciding what processes should be measured can be difficult, and therefore it is important that the organization chooses the right people to make these decisions, meaning that those people should have sufficient knowledge on the organization. It is common that the processes and activities chosen are those that are critical and require constant measuring and monitoring. For KPI's to be used successfully, they need to be a part of a Performance Measurement System (PMS). When developing these measures, it is important to have knowledge of what types and applications of measuring that are available.

\section{Business PERFORMANCE MANAGEMENT}

For a business to get the most out of a BI and RTBI implementation there is a need for focusing on the processes. Business Performance Management (BPM) is looked at as the new approach to business intelligence. BPM can also be known by names such as enterprise performance management or corporate performance management. Furthermore, a BPM standards group was established in 2003, in order to help the industry understand the concept. It offers an organization an approach that is IT-enabled, in order to effectively formulate and execute their strategy [26].

Business Performance Management focuses on the whole enterprise and BPM solutions run on timely data that provides support for operational, strategic and tactical decision- making, whereas BI provides support for strategic and tactical decision-making. Although it includes data warehousing, it also requires a reactive monitoring component. BPM includes DW but it also requires a brand new set of solutions that rely on different technologies and deeply impact on the overall architecture of the BI platform [30]. Data warehousing will function together with an analysis tool, but the problem is that it does not cover the whole need of the business. DW is not enough to this end since its technology is neither suitable for the grain nor for the freshness of the collected information, that should quickly flow throughout the different levels of the company. The four core processes the BPM framework consists of are:

- $\quad$ Strategize

- Plan

- Monitor and analyze

- Take corrective action

These four core processes form a closed loop that captures business strategy, which is then translated into strategically aligned business operations.

\section{CONCLUSION AND FUTURE WORK}

There is a big potential for a real-time business intelligence implementation as today's decisions are taken on a poor foundation. A real-time business intelligence implementation can result in significant benefits for the organization, by reducing the time spent making a decision, and by giving the decision-maker sufficient information for his decisions. That will result in a more effective decision process and reduced costs, as the decisions are made in a timely manner in a competitive environment.

There are potential challenges related to a real time business intelligence solution: processes are manual, employees are afraid of losing their relationship to current numbers, there needs to be consensus on what should be measured in real time, and the IT architecture lacks the main component of a real time business intelligence solution.

A crucial challenge is the fact that the organization has manual processes resulting in data having to be physically punched into the systems. For a real time business intelligence implementation, these processes need to be automated. It is also important that the strategy of the real time BI solution is aligned with the organizational strategy. With automated processes, the organization will have information systems that can speak with each other, and provide faster and more accurate information to the decision-maker.

An organization needs to pick the right processes to measure, which is difficult and critical to succeed. It is important that the correct people with sufficient knowledge in the organization choose these indicators and discuss their opinions. 
The core component of a real time business intelligence solution is a data warehouse, and that has to be in place before starting the adaptation of such a system. That data warehouse also needs to be prepared for real time.

By being able to see the organizational needs and the value of such a support system for decisions, as well as addressing the challenges that will occur, we believe that the decision processes will be more effective and that the decision-makers will be able to make faster decisions with more information to base them on.

By adding the layer of real-time business intelligence, the decision-maker will have access to correct and fresh data at all times. Decision-makers with more information available, make faster decisions. By improving the decision process, organizations are able to gain benefits. The value of improving the decision processes is reducing time spent retrieving information and increasing response time to customers, which is beneficial to the company in terms of reduced costs and more satisfied customers.

\section{REFERENCES}

[1] Atre, S. (2003).The Top 10 Critical Challenges for Business Intelligence Success. Computerworld Whitepaper, 1-8.

[2] Azvine, B., Cui,Z., \& Nauck,D. D. (2005). Towards real-time business intelligence. BT Technology Journal, 23(3), 214-225. doi: 10.1007/s10550-005-0043-0.

[3] Beatham, S., Anumba, C., Thorpe, T., \&Hedges, I. (2004). KPIs: A critical appraisal of their use in construction. Benchmarking: An International Journal, 11(1), 93-117.

[4] Böhnlein, M., \& Ulbrich-vom Ende, A. (2000). Business Process Oriented Development of Data Warehouse Structures. Data Warehousing 2000, 3-21.

[5] Breslin, M. (2004). Data Warehousing Battle of the Giants: Comparing the Basics of the Kimball and Inmon Models. Business Intelligence Journal, 9(1), 6-20.

[6] Cleland, D. I., \& King, W.R. (1983). System Analysis and Project Management ( $3^{\text {rd }}$ ed.): McGraw-Hill Book company.

[7] Creswell, J. W. (2009). Research design: qualitative, quantitative, and mixed methods approach.

[8] Davenport, T. H. (2010). Business Intelligence and Organizational Decisions. International Journal of Business Intelligence Research, 1(1), 1-12.

[9] Dube, L., \& Robey, D. (1999). Three cultural perspectives on the organizational practices of software development. Accounting, Management And Information Technologies, 9(4), 223-259.

[10] Eisenhardt, K. (1989). Making Fast Strategic Decisions in High-Velocity Environments. The Academy of Management Journal, 32(3), 543-576.

[11] Frolick, M. N., \& Ariyachandra, T. R. (2006). Business Performance Management: One Truth. Information Systems Management, 23(1), 41-48.

[12] Golfarelli, M., Rizzi, S., \& Cella, I. (2004). Beyond data warehousing: what's next in business intelligence? Paper presented at the Proceedings of the $7^{\text {th }}$ ACM international workshop on Data warehousing and OLAP, Washington, DC, USA.

[13] Grover, V., Jeong, S. R., Kettinger, W. J., \& Teng, J. T. C. (1995). The implementation of business process reengineering. Journal of Management Information Systems, 12(1), 109-144.

[14] Guba, E. G. (1990). The alternative paradigm dialog (pp. 17-30). Newbury Park, CA: Sage Publications, Inc.

[15] Hackathorn, R. (2004). The BI Watch: Real-Time to RealValue. DM Review 14(1).

[16] Hammer, M. (1990). Reeningeering work: Don't Automate, Obliterate. Harvard Business Review.

[17] Henderson, J., \& Venkatraman, N. (1993). Strategic Alignment: Leveraging information technology for transforming organizations. IBM systems journal, 1-13.

[18] Hill, A., Ariyachandra, T., \& Frolick, M. (2011). 10 Principles to Ensure Your Data Warehouse Implementation is a Failure. International Journal of Business Intelligence Research, 2(2), 37-47.

[19] Imhoff, C. (1999). The Corporate Information Factory Retrieved 16.02, 2012.

[20] Inmon, W. H., Imhoff, C., \& Sousa, R. (2001). Corporate information factory: John Wiley \& Sons.

[21] Markus, M. L. (2004). Technochange Management: Using IT to Drive Organizational Change. Journal of Informatian Technology, 19(1), 4-20.

[22] Massa, S., \& Testa, S. (2005). Data warehouse--inpractice: exploring the function of expectations in organizational outcomes. Information \& Management, 42, 709-718.

[23] Olsen, D. H. (2011). Decision making and judgment under uncertainty; Implications for the design of system decision support. Working Paper. Department of Information Systems. University of Agder.

[24] Negash, S. (2004). Business Intelligence. Communications of the Association for Information Systems, 13, 177-195.

[25] Rodrigues, L. C. (2002). Business Intelligence: the management information system next step. Anais of the Internatcional Conference on Management Information Systems Incorporating GIS \& Remote Sensing, 269-278.

[26] Rosser, B. (2010). BPM Technology and Tools Key Initiative Overview Retrieved May 18th, 2012

[27] Tapscott, D. (2008). Business Intelligence: Actionable Insights for Business Decision Makers. New Paragdim Learning Corporation.

[28] Turban, E., Sharda, R., \& Delen, D. (2011). Decision Support and Business Intelligence Systems ( $9^{\text {th }}$ ed.): Pearson Education, Inc.

[29] Turban, E., \& Volonino, L. (2010). Information Technology for Management. New Jersey: John Wiley \& Sons. Inc.

[30] Ultimus. (2003). An Introduction to BPM. Whitepaper.

[31] Vortex-Technologies. (2004). Business Intelligence for the Real Time Enterprise Retrieved 10.02, 2012, from http://www.vortexindia.com/Downloads/RealtimeBI.pdf.

\section{Authors' Profiles}

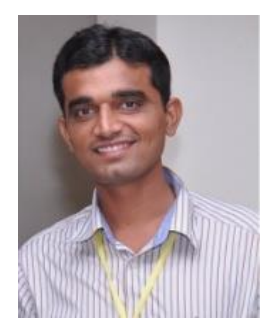

Darshan M. Tank: Lecturer of Information Technology at L E College, Morbi, Gujarat, India. My areas of interest include Business Intelligence, Data and Knowledge Mining, Real-Time Data Warehouse, Decision Support System and Information Retrieval. 